\title{
Effectiveness of atorvastatin in acute therothrombotic cerebral infarction
}

\begin{abstract}
Introduction: Cerebrovascular Diseases (CVD) constitute one of the most important health problems on a global scale and in Cuba they occupy the third cause of death and the first cause of disability.

Objective: To evaluate the use of atorvastatin in the acute phase of atherothrombotic cerebral infarction.

Method: A prospective longitudinal study was carried out in patients who attended the on-call department of the Julio Trigo López Hospital and were diagnosed with acute atherothrombotic cerebral infarction, who were randomly administered with prior informed consent: $0,20 \mathrm{mg}$ or $40 \mathrm{mg}$ of atorvastatin , they underwent CAT (Computerized Axial Tomography) of the skull, which was repeated on the third day and at 30 days, the value of PCR (C Reactive Protein) was determined in on-call body, on the fifth day and at 30 days, they were clinically evaluated according to the NIHSS scale (National Institute of Health Stroke Scale) in on-call body, daily during their admission and 30 days later.
\end{abstract}

Results: The size of the infarct area decreased by $19.4 \%$ with $40 \mathrm{mg}$ of atorvastatin as did the CRP value which was reduced by $16 \mathrm{mg} / \mathrm{Ll}$. The clinical assessment (NIHSS scale) was reduced according to the dose of atorvastatin by slightly more than 8 points.

Conclusions: The decrease in infarct area was directly proportional to the dose of atorvastatin used, just as the CRP values were lower and the favorable clinical evolution was associated with the use of this.

Keywords: atherothrombotic cerebral infarction, atorvastatin, C-reactive protein, computed tomography, infarct size, NIHSS, clinical assessment
Volume II Issue 6 - 202 I

\author{
Dr. Máximo Roiz Balaguer, Dr. lleana Morales \\ Barrabia \\ 'Second degree specialist in internal medicine, Assistant lecturer, \\ Master in successful longevity, Julio trigo lópez clinical surgical \\ teaching hospital, Cuba \\ ${ }^{2}$ First degree specialist in internal medicine, assistant lecturer, \\ master in successful longevity, Julio trigo lópez clinical surgical \\ teaching hospital, Cuba
}

Correspondence: Dr. Máximo Roiz Balaguer, Second degree specialist in internal medicine, Assistant lecturer, Master in successful longevity, Julio trigo lópez clinical surgical teaching hospital, Cuba, Email mroizb@infomed.sld.cu

Received: October 26, 2021 | Published: December 13, 202 |

\section{Introduction}

Cerebrovascular Diseases (CVD) constitute one of the most important health problems in all developed countries and in our country. Multiple resources are employed in order to attenuate the loss of human lives, which reaches considerable levels every year, and the degree of disability that these patients present. In the last three decades there has been an increase in the gross rates of death from these causes, with a tendency to shift death from these causes to earlier ages of life.

In Cuba they occupy the third place among the causes of death, ${ }^{2}$ as in the USA and the rest of the countries of the so-called first world, ${ }^{3}$ being the first cause of disability similar to the United States of America and Spain.

On a world scale, the population aged 60 years and over is increasing by $3 \%$ annually compared to a total increase of $1.9 \%$; it is estimated that in the year 2025 it will amount to 1121 million, equivalent to $13.7 \%$ of the general population. In Cuba it is even more pressing because our population is aging and the total population is not growing and is likely to decrease; the elderly population is currently close to $21 \%{ }^{4}$

The incidence of CVD increases with age, and mortality increases exponentially with age, virtually doubling every five years. It is the most common neurological disease, with a global average incidence of 200 cases per 100000 population each year, and a prevalence of 600 cases per 100000 . $^{5}$

Because of its magnitude and impact, this disease has been included among the priorities of the health programs of the World Health
Organization (WHO) and the Pan American Health Organization (PAHO).

In the last 20 years, the incidence of these has remained stable, but with a sustained reduction in mortality, attributable to the impact of better management of atherogenic risk factors and the introduction of new therapeutic measures: fibrinolytic, surgical and endovascular ${ }^{6-8}$ which are still not accessible in most of the hospital care in Cuba.

If statins are applied in the acute phase of the stroke, that is, during the first hours following the stroke, the administration of these would aim to stabilize the atheromatous plaque and thus promote the recovery of neurons that die during the acute phase of these episodes; Moreover, statins are very potent anti-inflammatory drugs that prevent the progression of atheromatosis in the acute phase of stroke, where there is a very important inflammation, inhibiting the socalled pleiotropic effects, most of which are related to inflammatory phenomena. Anoxic and necrotic brain cells cause damage to the still viable brain tissue, the immune system causes damage to the brain through an inflammatory reaction mediated by the vascular system. Damage to the blood vessel at the site of the blood clot attracts inflammatory blood elements to the site. Among the first blood elements to arrive are leukocytes that are coated with immune system proteins that bind to the blood vessel wall at the site of injury. After binding, the leukocytes penetrate the endothelial wall, pass through the blood-brain barrier, and invade the substance of the brain causing additional injury and brain cell death. ${ }^{9}$

Monocytes and macrophages release inflammatory chemicals (cytokines, interleukins, and tissue necrosis factors) at the site of injury. These chemicals make it more difficult for the body to naturally 
dissolve a clot that has caused a stroke by deactivating anticoagulation factors and inhibiting the release of natural tissue plasminogen activator. $^{10}$

Statins have an antithrombotic effect, which translates into a reduced tendency to thrombus formation after atheromatous plaque rupture. This action is achieved through numerous mediators: decreased fibrinogen levels, reduced tissue factor production, decreased platelet thrombus formation and improved fibrinolysis, regulating the fibrinolytic balance by increasing tissue plasminogen activator (tPA) and simultaneously inhibiting plasminogen activator inhibitor (PAI). ${ }^{11}$

It is also known to increase the number of endothelial smooth muscle cells and the expression of pro-collagen type I and reduce the proliferation and activation of macrophages. ${ }^{12}$

There is evidence that statins decrease certain markers of inflammation including $\mathrm{C}$-reactive protein (CRP), soluble intracellular adhesion protein and interleukin- $6 .^{13}$

Therefore, the objective of its use in the acute phase of CVD is to reduce endothelial inflammation, to reduce the area of ischemic penumbra, to save brain tissue and consequently to reduce mortality and disability that frequently accompany this entity.

\section{Methods}

A prospective descriptive study of longitudinal cohort was carried out between January 2018 and July 2020 in the hospital Julio
Trigo Lopez. The universe of the research consisted of all patients diagnosed with acute atherothrombotic cerebral infarction who gave their consent and were excluded those who presented complications or did not want to continue in the same.

The procedure used included the random administration of 0.1 or 2 tablets of atorvastine $(20 \mathrm{mg})$ from the on-call department, where a Computerized Axial Tomography (CAT) of the skull was also performed, which was repeated on the third day of admission and at 30 days, C-reactive protein (CRP) at the beginning, third day and 30 days, as well as the clinical evaluation of the patient according to the National Institute of Health Score Scale (NIHSS) daily during the time of admission and at 30 days in the outpatient clinic.

An appendix was applied to take variables of interest such as: age, sex, smoking habit, alcohol intake, risk factors such as HT and diabetes mellitus, size of cerebral infarction, CRP value and clinical assessment score according to the NHISS.

The results were presented in the Excel system, we used the WORD text processor of Windows and the statistical technique of analysis of variance (ANOVA) was used.

\section{Results}

The distribution of the 134 patients studied was almost similar in both sexes ( 69 women and 65 men), according to age groups, the male sex predominated in those under 60 years of age with $68.7 \%$ and in those over 60 years of age the female sex predominated with $57.8 \%$ of the cases (Table 1).

Table I Distribution by sex and age groups

\begin{tabular}{|c|c|c|c|c|c|c|c|c|c|c|c|c|c|}
\hline \multirow{3}{*}{ Sex } & \multicolumn{13}{|c|}{ Age groups } \\
\hline & \multicolumn{2}{|l|}{$31-40$} & \multicolumn{2}{|c|}{$41-50$} & \multicolumn{2}{|c|}{$51-60$} & \multicolumn{2}{|c|}{$61-70$} & \multicolumn{2}{|c|}{$71-80$} & \multicolumn{2}{|c|}{+80} & \multirow{2}{*}{$\begin{array}{l}\text { total } \\
\mathbf{n}\end{array}$} \\
\hline & $\mathbf{n}$ & $\%$ & $\mathbf{n}$ & $\%$ & $\mathbf{n}$ & $\%$ & $\mathbf{n}$ & $\%$ & $\mathbf{n}$ & $\%$ & $\mathbf{n}$ & $\%$ & \\
\hline women & -- & -- & -- & -- & 10 & 14,49 & 26 & 37,68 & 23 & 33,33 & 10 & 14,49 & 69 \\
\hline men & I & 1,53 & 3 & $4,6 I$ & 18 & 27,69 & 25 & 38,46 & 10 & 15,38 & 8 & 12,30 & 65 \\
\hline total & I & 0.75 & 3 & 2,24 & 28 & 20,90 & 51 & 38,06 & 33 & 24,62 & 18 & 13,43 & 124 \\
\hline
\end{tabular}

The relationship between sex and risk factors shows that almost $1 / 5$ of men consumed alcohol and more than half were smokers, as well as slightly more than a third of both sexes were smokers, we observed a high prevalence of Diabetes Mellitus with $20.14 \%$ with a slight predominance of the male sex and AHT showed a clear predominance in patients with $61.19 \%$ and there was also greater affectation in the male sex with $69.23 \%$ (Table 2).

Table 2 Distribution according to gender and risk factors

\begin{tabular}{|c|c|c|c|c|c|c|c|c|c|}
\hline \multirow{3}{*}{ Sex } & \multicolumn{9}{|c|}{ Risk Factors } \\
\hline & \multicolumn{2}{|c|}{ Diabetes mellitus } & \multicolumn{2}{|c|}{ Hypertension arterial } & \multicolumn{2}{|c|}{ Smoking } & \multicolumn{2}{|c|}{ Alcohol } & \multirow{2}{*}{$\begin{array}{l}\text { TOTAL } \\
\mathbf{n}\end{array}$} \\
\hline & $\mathbf{n}$ & $\%$ & $\mathbf{n}$ & $\%$ & $\mathbf{n}$ & $\%$ & $\mathbf{n}$ & $\%$ & \\
\hline Female & 13 & 18,84 & 37 & 53,62 & 14 & 20.29 & 2 & 2,85 & 69 \\
\hline Male & 14 & 21,53 & 45 & 69,23 & 34 & 52.3 & 12 & 18,46 & 65 \\
\hline TOTAL & 27 & 20,14 & 82 & 61,19 & 48 & 35,82 & 14 & 10.45 & 134 \\
\hline
\end{tabular}

The infarcted brain area and its relation to the dose of atorvastatin applied indicate a decrease of $4.8 \%$ between baseline and 30 days after the acute event in patients who did not receive any dose, while the difference was greater in those who took 1 tablet $(20 \mathrm{mg})$ being $11.7 \%$ and increases even more in those who received 2 tablets (40 $\mathrm{mg}$ ) to $19.4 \%$ (Table 3 ). 
Table 3 Distribution according to atorvastatin dose and infarct area decrease

\begin{tabular}{lllll}
\hline & Dose & N & Media & $\begin{array}{l}\text { Standard } \\
\text { deviation }\end{array}$ \\
\hline $\begin{array}{l}\text { Percentage } \\
\text { difference }\end{array}$ & No tablet & 46 & 4.8556 & 1.81322 \\
$\begin{array}{l}\text { infarcted } \\
\text { area }\end{array}$ & I tablet & 42 & 11.6895 & 1.50882 \\
(Home -30 days) & 2 tablets & 46 & $19.378 \mathrm{I}$ & 2.94319 \\
& Total & 134 & 11.9829 & 6.42313 \\
\hline
\end{tabular}

The reduction of the CRP value with the use of atorvastatin at baseline and 30 days after the event is observed in the mean differences, which are different for the 3 doses administered, with the smallest difference for patients who did not receive any dose at $8.5 \mathrm{mg} / \mathrm{L}$, increasing to $13.4 \mathrm{mg} / \mathrm{L}$ for those who took 1 tablet and reaching $16.1 \mathrm{mg} / \mathrm{L}$ in the group that took 2 tablets (Table 4).

Table 4 Distribution according to atorvastatin dose and pcr reduction

\begin{tabular}{llcll}
\hline & Dose & N & Media & $\begin{array}{l}\text { Standard } \\
\text { deviation }\end{array}$ \\
\hline No tablet & 46 & 8.517 & $3.88 \mathrm{II}$ \\
$\begin{array}{l}\text { Pifference } \\
\text { (Start }-30\end{array}$ & I tablet & 42 & 13.409 & 4.1002 \\
days) & 2 tablets & 46 & 16.109 & 2.8537 \\
& Total & 134 & 12.656 & 4.8232
\end{tabular}

Clinical assessment of patients according to the NIHSS scale indicates that the mean differences at baseline and 30 days are lower for those who received no dose (4.7) relative to the remaining doses, and the results do not differ statistically for the 1-tablet (8.9) and 2-tablet (8.0) groups of patients (Table 5).

Table 5 Distribution according to atorvastatin dose and nihss value

\begin{tabular}{lllll}
\hline & Dose & N & Media & $\begin{array}{l}\text { Standard } \\
\text { deviation }\end{array}$ \\
\cline { 2 - 5 } $\begin{array}{l}\text { NIHSS } \\
\text { Difference } \\
\text { (Home }-30\end{array}$ & No tablet & 46 & 4.67 & 2.161 \\
days) & I tablet & 42 & 8.86 & 4.683 \\
& 2 tablets & 46 & 8.02 & 1.994 \\
& Total & 134 & 7.13 & 3.604 \\
\hline
\end{tabular}

\section{Discussion}

In our study, the distribution of patients behaved similarly to that of González-Piña ${ }^{3}$ and in correspondence to the distribution of the population of the Arroyo Naranjo ${ }^{4}$ municipality, age is considered an atherogenic risk factor due to vascular aging, the deficiency of tissue repair mechanisms and organic dysfunction as well as the greater time of exposure to other risk factors with the increase in population aging and the presence of atheroma plaques, Other studies such as the Chilean health survey ${ }^{14}$ report that this disease is more frequent in men globally but increases in elderly women as the protective role of estrogens disappears, which causes a rapid decrease in bone mass, vasomotor instability and psychological symptoms that increase cardiovascular risk.

Alcohol consumption in patients was $10.45 \%$, close to the $9.5 \%$ reported by Gonzalez Mendez ${ }^{15}$ and close to the $11.26 \%$ reported by $\mathrm{Roa}^{16}$ in Chile, which is related to increased risk of stroke due to elevated blood pressure and the presence of arrhythmias, Although Spanish studies report that moderate alcohol consumption of less than 30 grams per day has a protective effect on the risk of ischemic stroke, ${ }^{17}$ also Gonzalez Mendez ${ }^{15}$ reported for smoking 41.3\%, higher than the report of our work of $35.82 \%$, It is demonstrated that this habit favors acquired hypercoagulability by increasing blood viscosity, fibrinogen and platelet aggregation as well as decreases high density lipoprotein with endothelial damage and induces arterial hypertension, In the same study it is also noted that $82.5 \%$ of patients were hypertensive, higher than $61.19 \%$ found in this study, HT is the most important modifiable risk factor for stroke, is proportional to the degree of hypertension and doubles for each increase of $10 \mathrm{~mm} \mathrm{hg}$.

Diabetes mellitus is an independent risk factor for ischemic stroke and is related to a greater susceptibility to atherosclerosis and a higher prevalence of atherogenic factors.

Although we have not found studies in which the size of acute cerebral infarction at the beginning and at 30 days is evaluated, we consider that the use of atorvastatin reduces the infarcted area and is a good therapy to save brain tissue, and the higher the dose used, the more significant reduction in the affected area was achieved.

CRP is a protein indicator of inflammation that rises rapidly in the acute phase and when it ceases, it also decreases rapidly, which is why it is useful as a marker of evolution. ${ }^{17}$ High serum concentrations of CRP on admission of a patient with cerebral infarction are associated with a poor evolution in the first hours and following days. ${ }^{18}$

Sequeiros Chirinos and Pena Sánchez in their studies showed that high CRP values were related to an unfavorable evolution, higher mortality and stroke recurrence, as well as worse prognosis in older patients. ${ }^{19,20}$

In our study, the use of atorvastatin at a higher dose decreased the CRP concentration and the evolution of the patients was better.

It is known the correlation that exists between the volume of cerebral infarction and the NIHSS scale score, the higher the value on this scale the worse the long-term prognosis, in a study conducted in Mexico. ${ }^{19}$ it was found that among the predictive factors of disability and death 30 days after acute cerebral infarction was the high values of the NIHSS scale, in this period in our work the decrease in the value of the NIHSS scale was related to the administration of atorvastatin, no deaths were reported and the disability present in patients decreased.

\section{Conclusion}

The decrease in the radiologically infarcted area was directly proportional to the dose of atorvastatin used, as well as the values of acute phase reactant (CRP) were lower and the favorable clinical evolution was associated with the use of this with a reduction in disability and mortality due to CVD.

\section{Recommendations}

At present, thrombolysis is not available in most Latin American hospitals and in Cuba, as well as mechanical thrombectomy due to its high cost. We consider that this drug could be useful in the treatment of the acute phase, so it would be necessary to extend the study with a larger number of patients and an increase in the dose of atorvastatin.

\section{Acknowledgments}

None. 


\section{Conflicts of interest}

The authors report no conflict of interest concerning the materials or methods used in this study or the findings specified in this paper.

\section{Author contribution}

Ciro Gonzalez Fernandez, Assistant Researcher. Master in Statistics. Performed statistical processing. Revised and approved the final version of the document.

\section{References}

1. WHO (World Health Organization). The world health report 2018 , shaping the future. Geneva: World Health Organization. 2018.

2. Ministry of Public Health, National Directorate of Medical Records and Health Statistics. Health Statistical Yearbook, table 14, 2019.

3. González-Piña R, Landínez-Martínez D. Epidemiology, etiology and classification of cerebral vascular disease. ArchMed (Manizales). 2016;16(2):495-507.

4. Estudios y datos de la población cubana, Cuba y sus territorios 2019, Centro de Estudios de Población y Desarrollo, Oficina Nacional de Estadística e Información. 2020.

5. National Center for Medical Sciences Information. National Medica Library. Stroke. World Statistics Factograph health [Internet]. 2017;3(12):13.

6. Pigretti, Santiago.G., Alet, Matias J, Mamani. Carlos E, et al. Consensus on acute ischemic stroke MEDICINA. (Buenos Aires). 2019; 79(2):1-46.

7. Fernández-Travieso, Julio C. Cerebrovascular disease: incidence and current treatment. CENIC Journal. Ciencias Biológicas. 2014;45(3):152-177.

8. García Alfonso C, Martínez Reyes A, Martínez Reyes V, et al. Update in diagnosis and treatment of acute ischemic stroke. Universitas Medica. 2019; 60(3):41-57.

9. Laufs U, Gertz K, Dirnagl U, et al. Rosuvastatin, a new HMG-CoA reductase inhibitor, upregulates endothelial nitric oxide synthase and protects from ischemic stroke in mice. Brain Res. 2002; 942:23-30.
10. Squizzato A, Romualdi E, Dentali F, et al. Statins for acute ischaemic stroke. Cochrane Database of Systematic Reviews. 2011;10(8): CD007551.

11. Fleitas Estévez A S. Current trends in the use of statins en dyslipidemias and other extralipid effects. Rev Cubana Angiol Cir Vasc. 2017;18(2).

12. Vergallo R, Crea F. Atherosclerotic Plaque Healing. $N$ Engl $J$ Med. 2020;383:846-857.

13. G J Moon, S J Kim, Y H Cho, et al. Antioxidant effects of statins in patients with atherosclerotic cerebrovascular disease. J Clin Neurol. 2014;10(2):140-147.

14. Government of Chile, Ministry of Health. National Health Survey 2016-2017 First Results. National health survey 2016-2017 first results. Santiago de Chile, MINSAL. 2017.

15. González MéndezM, Blanco Aspiazu, M.A.Mora González, et al. Size of atherothrombotic cerebral infarction of the carotid territory according to its risk factors Rev Cub Med Mil. 2019; 48(2):e251.

16. Roa Castillo S, Otto Sanguineti M E, Ascencio Fernández E. Epidemiological characterization of patients with acute cerebral vascular disease in a hospital in Chile based on diagnosis-related group registries. Medwave. 2019;19(6):7668.

17. Ruiz-Giménez Na, Gonzalez Ruano Pa, Suárez Cb. Health System Therapeutic Information. 2002;26( 4).

18. Emberson J, Bennett D Statins. C-Reactive Protein concentration and the vascular benefits of statin therapy: an analysis of 20,536 patients in the Heart Protection Study. Lancet. 2011; 377(9764):469-476.

19. Sequeiros-Chirinos JM, Alva-Díaz CA, Pacheco-Barrios $K$, et al. Diagnosis and treatment of the acute stage of ischemic stroke: Clinical practice guideline of the Peruvian Social Security (EsSalud). Acta Med Peru. 2020;37(1):54-73.

20. PENA SANCHEZ, Marisol et al. The increase of C-reactive protein in patients with acute ischemic stroke varies with age. Rev Cubana Invest Biomed [online]. 2020;39(3):e391.

21. Murillo LM, Lizola J, Lepe L, et al. Predictive factors of functional disability and death at 30 days in subjects with acute cerebral infarction. Mexican Journal of Neuroscience, March-April. 2011;12(2):68-75. 